Broeckmann, A. ; Wintgens, T. ; Schäfer, A. I. (2005) Removal and fouling mechanisms in nanofiltration of polysaccharide solutions, Desalination, 178, 149-159.

\section{Removal and Fouling Mechanisms in Nanofiltration of}

\section{Polysaccharide Solutions}

A. Broeckmann ${ }^{\mathrm{a}, \mathrm{b}}$, T. Wintgens ${ }^{\mathrm{b}}$, A.I. Schäfer ${ }^{\mathrm{a}}$

"Environmental Engineering, University of Wollongong, NSW 2522, Australia, ph +61 24221 3385, fax +61 24221 4738, Schaefer@uow.edu.au

${ }^{\mathrm{b}}$ Institut für Verfahrenstechnik, RWTH Aachen University, Turmstrasse 46, 52056 Aachen, Germany, ph +49 24180 96233 , fax +492418092252

wintgens@ivt.rwth-aachen.de, andreas-broeckmann@gmx.de

\section{Abstract}

Tubular membrane filtration is an important process when feed waters with a relatively high solids conten are filtered. Such solids would normally have to be removed in a pre-treatment stage if spiral wound modules are to be used. High solids content occurs for example in high turbidity surface waters, wastewaters that contain fibrous materials or in waters where coagulants are added. Tubular membranes can be used directly in nanofiltration $(\mathrm{NF})$ and in this study fouling by a solution containing polysaccharides is examined.

The study was designed in view of a wastewater recycling application where polysaccharides like cellulose are a major constituent of the effluent organic matter (EfOM) and colloidal organics. The investigation was performed with various organic compounds and varying solution chemistry namely $\mathrm{pH}$ and ionic strength Two solutes in several concentrations have been used: Cellulose (particulate) and microcrystalline cellulose (colloidal) in addition with various $\mathrm{CaCl}_{2}$ and $\mathrm{NaCl}$ concentrations. The operating parameters investigated were cross flow velocity, transmembrane pressure (TMP) and $\mathrm{pH}$. Membranes were cleaned after each filtration experiment and flux recovery was measured.

As a general trend, it was observed that with increasing cellulose concentration fouling increases and that solution chemistry plays an important role in the association of foulants with the membranes. The permeability decreases for high and neutral $\mathrm{pH}$ conditions in the presence of salt ions. Calcium affects the flux more than sodium. The permeability at acidic $\mathrm{pH}$ values is relatively low and not influenced by the ions as much as for other $\mathrm{pH}$ conditions. Electrostatic interactions between membrane, salt ions and cellulose can explain this behaviour. Calcium ions were confirmed to play an important role in membrane fouling. Increasing cross flow velocity decreases the reversible fouling but increases the irreversible fouling.

Key words: nanofiltration, membrane fouling, process design, polysaccharides, tubular membranes

\section{Introduction}

Due to the limited availability of fresh water the reuse of wastewater is an important process which is necessary to close the water cycle and make efficient use of available water resources. Membrane filtration is a suitable technology to produce clean water from polluted water in sufficient quality and quantity. However, the Achilles heel of this technology is often the extent of fouling: Membrane performance becomes less efficient. Therefore, it is important that the process operates near its optimum condition to avoid excessive fouling.

Nanofiltration (NF) membranes were developed to achieve high divalent ion rejection with a low transmembrane pressure (TMP). The operating pressure is generally 5 to 30 bar and the rejected molecules can have a molecular weight of as low as $200 \mathrm{~g} / \mathrm{mol}$ which corresponds to an equivalent Stokes diameter of approximately $1 \mathrm{~nm}$. NF membranes are neither entirely dense nor entirely porous so their retention mechanisms are determined by both size exclusion (porous membranes) and sorption and diffusion (dense membranes). A special feature of NF membranes is their selectivity regarding ions, with monovalent ions having a higher ability to pass through the structure than divalent ions. In case of organic molecules retention cannot be predicted and explained as easily. Affinity to the membrane, molecular weight, surface characteristics and molecular shape also play an important role and retention requires to date experimental investigations.

The type of membrane used for a particular application is determined by the required flux, feed fouling potential, interactions with divalent cations, electrostatic repulsion and attraction, hydrodynamic conditions, solution chemistry amongst other considerations. Wastewater filtration is carried out with ment achieved with tubular membranes [1]. The ability to clean the membrane effectively is one of the most important features which recommend this type of membrane for high solid load applications [1].

Membrane fouling is the major limitation in filtration of effluent water during reclamation of wastewater and is still not well understood. It is the sum of processes that cause a reduction of membrane performance and, if not controlled properly, serious problems occur resulting in premature replacement of membranes [2] or increasing energy consumption [3]. Fouling depends on several parameters, such as membrane characteristics, chemistry of the feed water, operating conditions $[4,5]$ and chencl-physical interactions between molecules and the membrane [1] Effects of fouling are for example flux decline at constant TMP, increasing TMP at constant permeate flux operation [5] and a change of the selectivity or retention [3]

Fouling can be classified as internal (pore) and external (surface) deposits or according to the cleaning ability as reversible and irreversible fouling. Pore blocking and adsorption on inner surfaces are caused by particles smaller than the pore size (internal). Particles larger than the pore size form cake or gel layers and adsorb on the membrane surface (external) [6]. A strict division of the different types is not possible as, in general, a combination of various foulants leads to the simultaneous occurrence of several fouling mechanisms. Fouling occurs in large time scales (days, hours), the more temporary phenomenon of concentration polarisation is built up in minutes or secos. While the inces or 作 itself a type of fouling it promotes adsorption, pore blocking and cake/gel layer formation and hence often is a fouling precursor [7]. Membrane lifetime is mostly limited by the irreversible fouling such as pore blocking or adsorption on inner surfaces [8].

Effluent organic matter (EfOM) characteristics in the feed water play an important role in membrane fouling in wastewater applications. The composition of EfOM is quite complex and heterogeneous. For example, it contains polysaccharides, proteins and humic substances as well as aminosugars, nucleic acids and cell components [4]. The polysaccharides have the greatest fouling potential [4, 6, 9-11]. EfOM includes organic colloids and macromolecules of a size less than $1 \mathrm{~nm}$ to several micrometers [10]. Especially particles in the range of $0.2 \mu \mathrm{m}$ to $3 \mu \mathrm{m}$ are known to cause serious fouling problems in NF and must be removed to improve membrane performance [12].

In suspended systems electrokinetic forces play an important role when describing particle In suspended systems electrokinetic forces play an important role when describing particle
interactions. There is a correlation between the filterability and the particle charge [13]. To measure interactions. There is a correlation between the filterability and the particle charge [13]. To measure
the surface electrical charge of colloidal size particles and membrane surfaces, streaming potential is widely used. The streaming potential is a function of the solution chemistry and can be manipulated by varying $\mathrm{pH}$ or inorganic salt (especially salts containing $\mathrm{Ca}^{2+}$ and $\mathrm{Mg}^{2+}$ ) concentration $[13,14]$. The streaming potential of Polyamide (PA) composite membranes is reported by several investigators $[15,16]$ all confirming the isoelectric point at $\mathrm{pH} 3$ (below negatively, above positively charged. Mosbye et al. [17] investigated properties of cellulose of different particle sizes $(5-76 \mu \mathrm{m})$. The conclusion was that the surface charge decreases from slightly negative $(-0.5 \mathrm{mV})$ to negative $(-4 \mathrm{mV})$ with between $\mathrm{pH} 2$ to 9 for all sizes. Recapitulating, there is an electrostatic repulsion at high and an electrostatic attraction at low $\mathrm{pH}$ values between the polyamide membrane surface and cellulose particles.

Seidel et al. [18] studied the flux decline caused by NOM (which also contained polysaccharides) on NF membranes with several permeate and cross flow velocities. Low cross flow velocity enhances the concentration polarisation and therefore the NOM and calcium concentrations in the boundary layer. This enhances NOM adsorption and interactions with the divalent ions and hence 
fouling and flux decline increase. NOM deposition in the absence of $\mathrm{Ca}^{2+}$ is only reported at high permeate velocity due to the fact that at low permeate velocities the electrostatic repulsion is large compared to the permeation drag $[14,18]$. Furthermore the charge of organic molecules and therefore the fouling potential can be manipulated with the presence of calcium ions due to charge screening [14]. Also, bridging between organic components and the membranes by calcium ions affects the fouling behaviour to some extent [14]. In general, one can say that increasing ionic strength [19], decreaing $\mathrm{pH}$, negative particle surface charge (while using PA membrane and especially the presence of divalent ions is expected to promote fouling. especially the presence of divalent ions is expected to promote fouling.

The feed solution in this study, as in many water recycling applications, has a relatively high colloids load and also a high fouling potential. The colloids are of organic nature, specifically polysaccharides, as commonly found in wastewater applications. Therefore the membranes used are tubular composite membranes with NF characteristics and fouling by such organic colloids under varying solution chemistries is investigated in detail.

\section{Materials and Methods}

2.1 Tubular Filtration Rig and Protocol

The experimental rig consisted of three tubular membrane modules (see Figure 1). The feed solution $(120 \mathrm{~L}$ tank) was cycled through the membrane modules with a high pressure pump (Lowara Pump SV 218F22). The feed flow and pressure were adjusted between a range from 2 to $40 \mathrm{~L} / \mathrm{min}$ (Buerkert, Easy Flow 8035) and a TMP of 1 to 16 bar (Buerkert, analog gauge) respectively. The pressure was also measured before entering the module; the pressure loss caused by the membrane modules was less than the instrument accuracy $(<<1 \%)$ and hence was neglected. The permeate flow was measured with an electronic balance (measuring the time for a fixed permeate volume). Conductivity, $\mathrm{pH}$, total organic carbon (TOC) a were analysed. Due to the heat exchanger unit the temperature was almost constant $\left(25.5^{\circ} \mathrm{C} \pm 1^{\circ} \mathrm{C}\right)$. The temperature was measured in the reservoir tank and was regulated by a thermostatic unit (Group Four Industries, Davian 757) with coolant (tap water). Slight variation in temperature was corrected with a temperature-permeability-equation. The experiments were carried out with the following protocol; for the first 30 minutes the membrane was rinsed with tap water followed by measuring the pure water permeability as a reference. Then an experiment with a particular feed solution was carried out until a steady state was reached or a minimum filtration time of $540 \mathrm{~min}$. After each experiment the mathe After each experite pure water perno pure water permeability before and after each experiment was used to characterize the extent of reversible fouling. If the wate permeability after the rinsing was too low ( $<95 \%$ of the initial flux) chemical cleaning was carried out. The chemical cleaning involved storage in acid-solution $\left(\mathrm{HNO}_{3}, \mathrm{pH} 3\right)$ and base-solution $(\mathrm{NaOH}, \mathrm{pH} 10)$ for at least one hour, followed by rinsing with tap water for 30 to 60 minutes. The difference between water permeability before and after the chemical cleaning characterized the extent of irreversible fouling. After the experiments the membrane was stored in tap water.

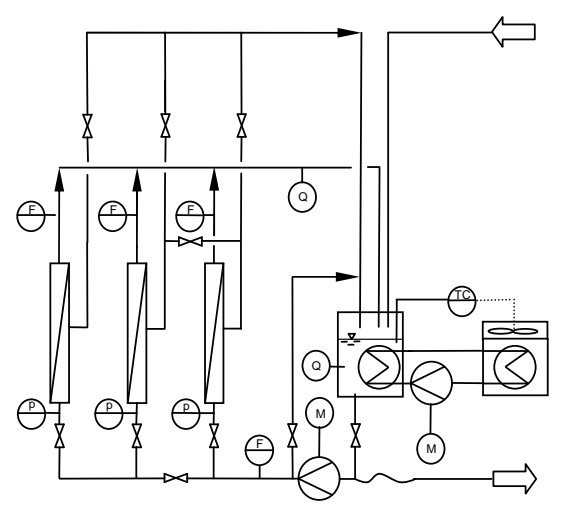

Figure 1: Flow sheet of the experimental rig

Because of the large particle size (macromolecules) the effect of the osmotic pressure was negligible in these experiments; the error is in the range of the total accuracy of the measurements [14].

During the experiments the TMP $(\Delta \mathrm{P})$, the temperature $(\mathrm{T})$ and the permeate flux $(\mathrm{J})$ were measured and flux values were then normalised to the standard temperature of $25^{\circ} \mathrm{C}$. The normalised permeability (L) was calculated as:

$$
L\left(T^{25.5^{\circ} \mathrm{C}}\right)=\frac{J(T)}{\Delta P} \cdot \exp \left[0.0155\left(T-25.5^{\circ} \mathrm{C}\right)\right] .
$$

Further, the nominalized permeability was compared with the pure water permeability at the beginning of each set of experiments. The order of experiments considered the fouling potential of the solutions; the lowest fouling potential was filtered first, the highest last. This assumed that the following solution fouled the membrane at least as much as the solution before. Initial experiments have shown that this assumption was justified and resulted in a minimal error in the results.

\subsection{Membrane Characteristics}

Hydrophobic PA nanofiltration membranes (type 7425 , diameter: $11 \mathrm{~mm}$, length: $600 \mathrm{~mm}$ membrane area: $0.02168 \mathrm{~m}^{2}$, membrane resistance $\mathrm{R}^{\mathrm{M}}: 2.7 \cdot 10^{13} \mathrm{~m}^{-1}$ ) of the company Berghof Filtrations- und Anlagentechnik (Eningen, Germany) have been tested. Table 1 summarizes the determined values for the 7425 membrane.

Table 1: Initial retention and initial permeability of the membrane type $7425,\left({ }^{\circ}:\right.$ Berghof, used membrane batches: ${ }^{1} 7425-1 ;{ }^{2} 7425-2 ;{ }^{3} 7425-3$ investigated in own experiments; $T=25.5^{\circ} \mathrm{C}, \mathrm{v}_{\mathrm{cos}}=1 \mathrm{~m} / \mathrm{s}$, $\mathrm{pH}=7$ )

\begin{tabular}{ccccc}
\hline Salt & $\begin{array}{c}c_{\text {Cation }} \\
{[\mathrm{g} / \mathrm{L}]}\end{array}$ & $\begin{array}{c}\text { TMP } \\
{[\mathrm{bar}]}\end{array}$ & $\begin{array}{c}\text { Retention } \mathrm{R}_{\text {salt }} \\
{[\%]}\end{array}$ & $\begin{array}{c}\text { Permeability } \\
{\left[\mathrm{L} /\left(\mathrm{h} . \mathrm{m}^{2} \cdot \text {.bar }\right)\right]}\end{array}$ \\
\hline $\mathrm{NaCl}$ & 1.38 & 20 & $<50^{0}$ & n.a. \\
& 9.83 & 20 & $<25^{0}$ & n.a. \\
& 19.67 & 20 & $<10^{0}$ & n.a. \\
$\mathrm{CaCl}_{2} \cdot 2\left(\mathrm{H}_{2} \mathrm{O}\right)$ & 0.050 & 5 & $60^{1}, 90^{2}, 92^{3}$ & $14^{1,2,3}$ \\
\hline
\end{tabular}


2.3 Chemicals, Polysaccharides and Background Solution

The chemicals that were used in the experiments are $\mathrm{NaCl}, \mathrm{CaCl}_{2} \cdot 2 \mathrm{H}_{2} \mathrm{O}, \mathrm{CaSO}_{4} \cdot 2 \mathrm{H}_{2} \mathrm{O}, \mathrm{HCl}, \mathrm{HNO}_{3}$ and $\mathrm{NaOH}$ solutions; all analytical grade (Sigma Aldrich/Merck, Australia). The solutions were prepared with tap water, which had a constant conductivity of $130 \mu \mathrm{S} / \mathrm{cm}$ and also a constant $\mathrm{pH}$ value of 7.7. The tap water contains approximately $16 \mathrm{mg} / \mathrm{L} \mathrm{Ca}^{2+}$ and $8 \mathrm{mg} / \mathrm{L} \mathrm{Na}^{+}$and $75 \mathrm{mg} / \mathrm{L}$ tota olids (TDS) [20].

Particulate cellulose with an average particle size of 20um (Merck, Australia) and colloidal microcrystalline cellulose (MCC) (Sigma Aldrich, Australia) are insoluble (in water, diluted acids, most organic solvents and in sodium hydroxide solution) polysaccharides that consist of 500 to 5000 glucose units (molecular weight per unit $162 \mathrm{~g} / \mathrm{mol}$ ). Approximately 60 to 70 percent of such cellulose chains form a micro fibril which is characteristic for plant structures [21]. In water the cellulose builds a three-dimensional matrix, consisting of millions of insoluble microcrystals that form an extremely stable gel (see Figure 2).

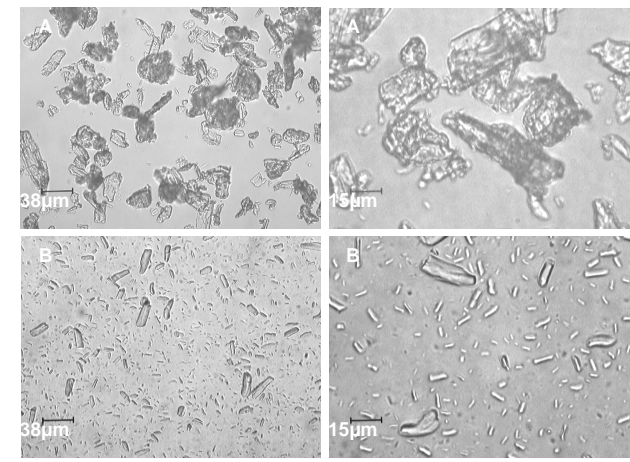

Figure 2: Light microscopy pictures of A: particulate cellulose $(20 \mu \mathrm{m})$; B: microcrystalline cellulose (MCC)

2.4 Water Quality Measurements and Analysi

The conductivity and the $\mathrm{pH}$ of every sample were measured with a Multiline P4 Set 3 instrument (WTW, Germany). UV/VIS absorbance and therefore the organic concentration of the feed solution was analysed with a UV-1700 Shimadzu spectroscope in combination with quartz cuvettes at a wavelength of $550 \mathrm{~nm}$. For the used chemicals there was no characteristic peak at a particula wavelength. However, the calibration curve of the UV absorbance measurements showed a linear relationship with concentration for the organic solutes used. Total organic carbon (TOC) analysis (Shimadzu TOC- $\mathrm{V}_{\mathrm{CSH}}$ analyser, non purgeable organic carbon (NPOC) mode) was carried out to measure also organic feed concentration. TOC analysis can only be carried out for MCC. 20umcellulose was not analysed because of the large particle size which caused rapid settling and as a result was not reproducible and time dependent.

To determine particle size distributions light microscopy was carried out with a Leica DM/RM optical microscope with a 50x to 1000x magnification and an integrated Panasonic video system for screenshots. To analyse the particle distribution an Ankersmid CIS-1 particle analyser which detects particles in the range of 1.2 to $150 \mu \mathrm{m}$ was used. The particles were analysed in a $2 \%$ (mass fraction) DI water solution.

\section{Results and Discussions}

\section{$3.1 \quad$ Particle Characterisation}

Prior to membrane filtration experiments it is important to know the nature of particles in solution well. Light microscopy gives a good representation of the particle sizes and the particle interactions (e.g. the ability to form large particles). The picture of particulate cellulose (Figure 2A) shows that three fractions of rectangular particles co-exist: $5 \mu \mathrm{m}, 20 \mu \mathrm{m}$ and aggregates with a size $>40 \mu \mathrm{m}$. The MCC particles had a reasonably consistent size of approximately $2 \mu \mathrm{m}$ as can be seen in Figure 2B while only a few particles had a size of $20 \mu \mathrm{m}$. The difference between both samples was smaller than expected.

Two modes of particle analysis were investigated: Number-size and area-size distributions. The area-size distribution is important for fouling caused by adsorption, in particular where other contaminants are taken up by the colloids. Number-size distribution is important for pore blocking, cake and la la behaviour of the cellulose and the MCC particles (see Figure 3A). They had a significant peak at $1 \mu \mathrm{m}$, only a few particles had a size in the range 5 to $10 \mu \mathrm{m}$. Analysing the area size distribution (Figure 3B) shows that the cellulose area is dominated by three fractions: $5 \mu \mathrm{m}, 20 \mu \mathrm{m}$ and $50 \mu \mathrm{m}$ which confirmed the results of the microscope analysis. Two area fractions of MCC particles of approximately $5 \mu \mathrm{m}$ and $20 \mu \mathrm{m}$ were found.
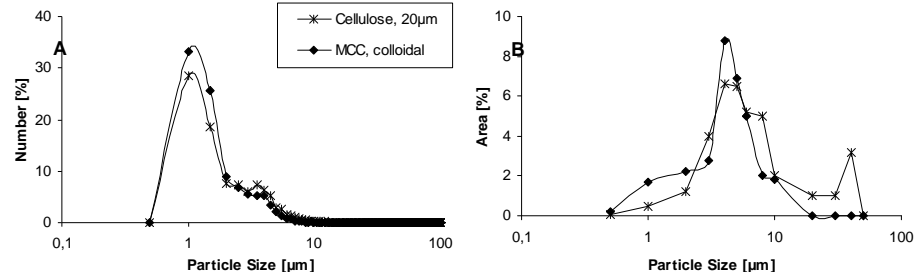

Figure 3: Particle distribution in form of $\mathrm{A}$ : number and $\mathrm{B}$ : area for cellulose and colloidal $\mathrm{MCC}$

The results of the particle analysis relevant to nanofiltration were that the particulate cellulose was too large to cause pore blocking; MCC was marginally smaller in size due to the presence of some smaller particulates which would be expected to form a less permeable cake. Both colloids were most likely to form layers on the membrane surface. The presence of ions was expected to enhance aggregation effects which were visible in the particle analysis. In tap water cellulose forms loose aggregates but there appeared to be no gel forming at the concentration studied (two weight percent).

3.2 Particulate Cellulose Filtration

One of the main aims of each set of experiments was to determine at which conditions fouling occurred for those solutes by varying cross flow velocity, concentration and solution chemistry.

Changing the cross flow velocity from $1 \mathrm{~m} / \mathrm{s}$ to $2 \mathrm{~m} / \mathrm{s}$ had a quite dramatic effect on flux decline (see Figure 4). Several cellulose concentrations were analysed regarding the steady state flux and the type of fouling that occurred. Only reversible fouling was observed at a concentration of $0.2 \mathrm{~g} / \mathrm{L}$ for the low velocity applications $(1 \mathrm{~m} / \mathrm{s})$. No irreversible fouling was found. At high cross flow velocity the situation was different; fouling occurred at the lowest investigated concentration. Irreversible fouling increased dramatically with increasing cellulose concentration. As expected the reversible fouling was sme the concentration polarisation. This was an optimization problem of reducing reversible fouling found at low velocities and the irreversible fouling that occurs at high velocities. The irreversible fouling at high cross flow velocities appeared to be caused by smaller particles which were forming a less permeable cake deposit than larger particles. On the one hand smaller particles were produced 
because of the increasing shear stress [22], while on the other hand the hydrodynamic forces allowed only smaller particle to enter the boundary layer and therefore to be deposited on the membrane surface $[2,23]$.
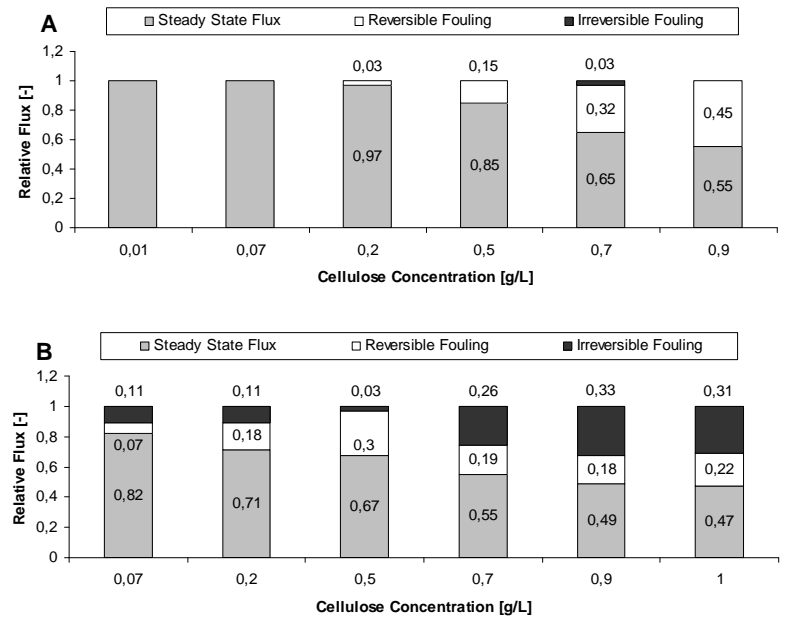

Figure 4: Relative Flux versus cellulose concentration for two different cross flow velocities A: $1 \mathrm{~m} / \mathrm{s}$ and $\mathrm{B}: 2 \mathrm{~m} / \mathrm{s}\left(\mathrm{T}=25.5^{\circ} \mathrm{C}, \mathrm{TMP}=500 \mathrm{kPa}, \mathrm{pH}=7\right.$, tap water $)$, numbers on bars indicate percentage of the relative flux of the particular fouling

The change in flux decline as a function of solution chemistry ( $\mathrm{pH}$, salt concentration and type) is reported in Figure 5. It can be seen that the permeability at acidic conditions ( $\mathrm{pH} \mathrm{3}$ ) was not reported in Figure 5. It can be seen that the permeability at acidic conditions ( $\mathrm{pH}$ 3) was not
influenced by the presence of salt. It appears that electrostatic attraction between negatively charged particulates and positively charged membranes affected the fouling more than cation-cellulose interactions. It must be noted that the background solution was tap water which contained a small amount of calcium and sodium ions. This influenced the permeability to some extent. For the neutral ( $\mathrm{pH} \mathrm{7)}$ and alkaline ( $\mathrm{pH} \mathrm{10)}$ conditions the valency of the ions played an important role. There was nearly the same flux decline for $830 \mathrm{mgNa}^{+} / \mathrm{L}$ as for $60 \mathrm{mgCa}^{2+} / \mathrm{L}$, hence as expected calcium ions affected this trend more than the sodium ions. The strong influence of calcium ion also explains the irreversible fouling at $500 \mathrm{mgCa}{ }^{2+} / \mathrm{L}$. For these conditions the cation-cell
interactions were the dominating factor as previously published by Hong and Elimelech [14].

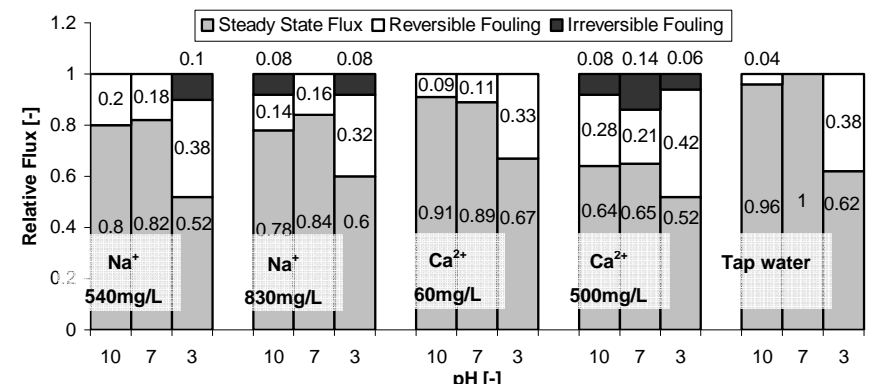

Figure 5: Relative flux versus $\mathrm{pH}$ and different feed solutions (numbers under the cations indicate ion concentration in $\mathrm{mg} / \mathrm{L}$ ), particulate cellulose concentration $0.07 \mathrm{~g} / \mathrm{L}, \mathrm{T}=25.5^{\circ} \mathrm{C}, \mathrm{TMP}=500 \mathrm{kPa}, \mathrm{v}^{\text {cross }}=1$ $\mathrm{m} / \mathrm{s}$, salts used: $\mathrm{NaCl}, \mathrm{CaCl}_{2} \cdot 2 \mathrm{H}_{2} \mathrm{O}$ ), numbers on and above bars mean percentage of the relative flux of the particular fouling

3.3 Microcrystalline Cellulose (MCC) Filtration

As described for the cellulose in Figure 5 similar investigations were carried out for the microcrystalline cellulose (MCC) also. The influences of the type and the concentration of cation on the flux decline for different $\mathrm{pH}$ conditions are summarized in Figure 6. In general, the effect of the presence of even small salt concentrations affected the permeability at high and neutral $\mathrm{pH}$ Because of the electrostatic attraction at low $\mathrm{pH}$ and the higher specific surface compared to cellulose $(20 \mu \mathrm{m})$, the flux decline was already relatively high in tap water and only a slight additional decline was observed with the presence of ions. The fouling of MCC colloids and aggregates at high $\mathrm{pH}$ (which were likely to be present in the solution at these conditions [11, 24, $25]$ ) was more obvious than for cellulose $(20 \mu \mathrm{m})$ presumably caused by the smaller size fractions present in microcrystalline cellulose. Sodium in solution influences the irreversible fouling at low and high $\mathrm{pH}$ to some extent. A possible explanation is that the solvent (tap water) contained also a low concentration of calcium, which caused significant fouling. The figure shows that even low salt concentrations had an influence on the flux decline and fouling behaviour. MCC reacted stronger
than cellulose $(20 \mu \mathrm{m})$ to $\mathrm{pH}$ variation and the presence of cations.

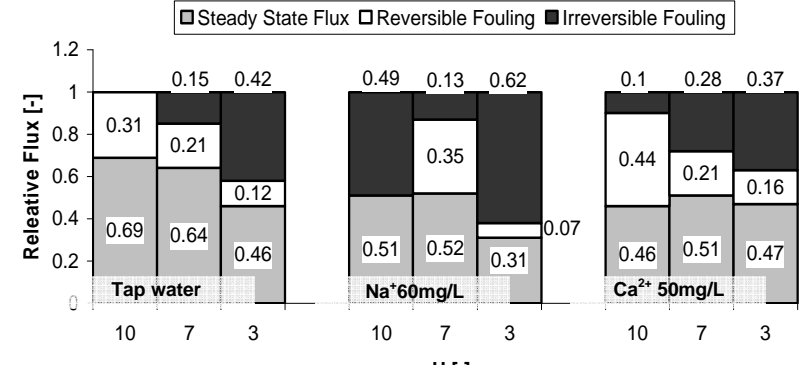

$\mathrm{pH}[-]$

Figure 6: Relative flux versus $\mathrm{pH}$ and feed solution (numbers behind the cations indicate ion concentration in $\mathrm{mg} / \mathrm{L}$ ) MCC concentration: $0.07 \mathrm{~g} / \mathrm{L}, \mathrm{T}=25.5^{\circ} \mathrm{C}, \mathrm{TMP}=500 \mathrm{kPa}, \mathrm{v}^{\text {cross }}=1 \mathrm{~m} / \mathrm{s}$, used salts: $\mathrm{NaCl}, \mathrm{CaCl}_{2} \cdot 2 \mathrm{H}_{2} \mathrm{O}$

\section{Conclusions}

The effect of changing operating conditions on the flux of tubular NF membrane was studied with several wastewater model solutions focused on filtering wastewater levels of potential foulants. The main research question was how dissolved, colloidal and particulate organics or polysaccharides affect the fouling under various solution chemistries and hydrodynamic conditions.

Increasing cross flow velocity reduced the concentration polarisation and therefore the reversible fouling [26]. On the other hand a higher velocity also increased the shear stress and due to the hydrodynamic forces only smaller particles were able to settle on the membrane surface [22]. As a result higher cross flow velocity reduced reversible fouling and promoted irreversible fouling. With increasing particulate cellulose and microcrystalline cellulose (MCC) concentration the fouling increased.

The $\mathrm{pH}$ conditions affected the permeability dramatically. At low $\mathrm{pH}$ the electrostatic attraction (polyamide is positively charged) and the model substances (particulate cellulose, MCC are negatively charged) decreased the permeability substantially. The presence of monovalent (sodium) and divalent (calcium) ions also affected the performance of the NF membrane. A general trend was that even a small amount of calcium ions affects the reversible 
and irreversible fouling which confirms previous studies for such membranes [14, 24, 27], while only highly concentrated sodium chloride solutions were able to influence the membrane performance. This could also be caused by an increasing osmotic pressure due to the high sodium concentration.

In summary, a moderate cross flow velocity, low multivalent ion concentration and neutral to high $\mathrm{pH}$ will assist the successful filtration of wastewaters containing polysaccharides.

\section{Acknowledgements}

This work is proudly supported by the International Science Linkages programme established under the Australian Government's innovation statement Backing Australia's Ability. It is funded by the Commonwealth Department of Education Science and Training for the project OzAquarec: Integrated Concepts for Reuse of Upgraded Wastewater in Australia (CG030025). It forms part of the European Union 5th Framework Project AQUAREC: Integrated Concepts for Reuse of Upgraded Wastewater (EVK1-CT-2002-00130).

The author would like to thank Jens Breidenbach (FH Köln, Germany) for the initial design of the tubular filtration rig and Dr. Werner Stooss (Berghof GmbH, Eningen, Germany) for the provision of membranes as well as technical support and useful discussions.

\section{References}

R. Rautenbach and T. Melin, Membranverfahren, 2004, Springer-Verlag.

[2] H. Evenblij and J. H. J. M. van der Graaf, Occurrence of EPS in activated sludge from a membrane bioreactor treating municipal wastewater, in: Nano and Micro Particles in Water and Wastewater Treatment, 2003, Zürich, Switzerland.

[3] B. Van der Bruggen, L. Braeken and C. Vandecasteele, Flux decline in nanofiltration due to adsorption of organic compounds, Separation and Purification Technology 29 (2002) 23-31.

4] C. Jarusutthirak, G. Amy and J.-P. Croue, Fouling characteristics of wastewater effluent organic matter (EfOM) isolates on NF and UF membranes, Desalination 145 (2002) 247255.

[5] A.L. Lim, and R. Bai , Membrane fouling and cleaning in microfiltration of activated sludge wastewater, Journal of Membrane Science 216 (2003) 279-290.

[6] C. Guell and R. H. Davis, Membrane fouling during microfiltration of protein mixtures, Journal of Membrane Science 119 (1996) 269-284.

[7] S. S. Sablani, M. F. A. Goosen, R. Al-Belushi and M. Wilf, Concentration polarisation in ultrafiltration and reverse osmosis: A critical review, Desalination 141 (2001) 269-289. D. J. Carlsson, M. M. Dal-Chin. P. Black and C. N. Lick, A surface spectroscopic study of membranes fouled by pulp mill effluent, Journal of Membrane Science 142 (1998) 1-11.

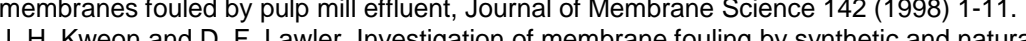
J. H. Kweon and D. Fat Micro Particles in Water and Wastewater Treatment, 2003 , Zürich, Switzerland.

[10] C. Laabs, G. Amy and M. Jekel, Organic colloids and their influence on low-pressure membrane filtration, in; Nano and Micro Particles in Water and Wastewater Treatment, 2003, Zürich - Switzerland.

[11] C. Jarusutthirak and G. Amy, Membrane filtration of wastewater effluents for reuse: effluent organic matter rejection and Membrane filtration of wastewater effluents for reuse: effluent organic matter rejection and fouling, Water Science and Technology 43 (2001) 225-232.

[12] S. te Poele, J. H. Roorda and J. H. J. M. van der Graaf, Influence of the size of foulants on the filterability of WWTP-effluent, in: Nano and Micro Particles in Water and Wastewater

[13] W. Wang and G. G. Chase, Using Zeta Potentials to Characterize Filter Performance Microscale Physiochemical Engineering Center (MPEC), University of Akron, 2004.

[14] S. Hong and M. Elimelech, Chemical and physical aspects of natural organic matter (NOM) fouling of nanofiltration membranes, Jounal of Membrane Science 132 (1997) 159-181.

[15] W. L. Walker, S. Bhattacharjee, E. M. V. Hoek and M. Elimelech, A novel asymmetric clamping cell for measuring streaming potential of flat surfaces, Langmuir 18 (2002) 2193-
[16] M. J. Ariza, A. Canas, J. Malfeito and J. Benavente, Effect of $\mathrm{pH}$ on electrokinetic and electrochemical parameters of both sub-layers of composite polyamide/polysulfone membranes, Desalination 148 (2002) 377-382.

[17] J. Mosbye, Fractionation and chemical analysis of fines, The Norwegian Pulp and Paper Research Institute, Trondheom, Norway.

[18] A. Seidel and M. Elimelech, Coupling between chemical and physical interactions in natural organic matter (NOM) fouling of nanofiltration membranes: implications for fouling control, Journal of Membrane Science 203 (2002) 245-255.

[19] K. L. Jones and C. R. O'Melia, Ultrafiltration of protein and humic substances: effect of solution chemistry on fouling and flux decline, Journal of Membrane Science 193 (2001) 163-173.

[20] Sydney Water Corporation, Sydney Water Analysis, www.sydneywater.com.au, accessed 06/02/2004.

[21] Klemm, Philip, Heinze and Wagenknecht, Comprehensive Cellulose Chemistry. Vol. 2, 1998, Weinheim.

[22] M. Mänttäri, L. Puro, J. Nuortila-Jokinen and M. Nyström, Fouling effects of polysaccharides and humic acid in nanofiltration, Journal of Membrane Science 165 (2000) $1-17$.

[23] A. G. Fane, P. J. Beatson and H. Li, Membrane fouling and its control in environmental applications, Water Science \& Technology (2000) 41 303-308.

[24] N. A. Wall and G. R. Choppin, Humic acids coagulation: influence of divalent ions, Applied Geochemistry 18 (2003) 1573-1582

[25] S. F. E. Boerlage, M. D. Kennedy, M. R. Dickson, D. E. Y. El-Hodali and J. C. Schippers, The modified fouling index using ultrafiltration membranes (MFI-UF): characterisation, filtration mechanisms and proposed reference membrane, Journal of Membrane Science 197 (2002) 1-21.

[26] M. Mänttäri and M. Nyström, Critical flux in NF of high molar mass polysaccharides and effluents from the paper industry, Journal of Membrane Science 170 (2000) 257-273.

[27] M. Nyström, L. Kaipia and S. Luque, Fouling and retention of nanofiltration membranes, Journal of Membrane Science 98 (1994) 249-262. 